\title{
Boas Práticas Visuais no Jornalismo: Um Guia para Profissionais de Comunicação ${ }^{1}$
}

Helena Carmona Gomes

Pontifícia Universidade Católica do Rio de Janeiro - PUC-Rio

Departamento de Comunicação Social - Bacharelado em Jornalismo

\section{Resumo}

Este trabalho investiga da importância do conhecimento na área de comunicação visual para profissionais do jornalismo, tanto por questões mercadológicas como a respeito da qualidade dos produtos jornalísticos. Busca respostas para o afastamento entre a função de jornalista e diagramador em autores como Vilém Flusser ( $O$ mundo codificado) e Nunes Freire ( $O$ design no jornal impresso diário). A partir dessa investigação, surge o produto prático do trabalho: um Guia de Boas Práticas Visuais para Jornalistas, fundamentado em autores como Rafael Cardoso (Design para um Mundo Complexo), Washington Dias Lessa (Dois Estudos de Comunicação Visual) e Rudolf Arnheim (Arte e Percepção Visual).

Palavras-chave: Design de notícias; jornalismo; jornalismo digital; diagramação; enunciação jornalística; comunicação visual.

\section{Introdução}

Este projeto consiste na elaboração de um Guia de Boas Práticas Visuais para Jornalistas. Profissionais do jornalismo já estão familiarizados com a figura do manual de redação, documento que define as principais diretrizes para produção textual dentro de um determinado veículo.

Levando em conta a diminuição das redações, o consequente processo de acúmulo de funções no mercado da comunicação, e ainda a aproximação entre as funções de jornalista e diagramador (NUNES FREIRE, 2009), o guia produzido como resultado desse trabalho visa a orientar jornalistas nessa área, na qual muitos têm pouca experiência ou conhecimento técnico, estabelecendo orientações básicas para o ganho - ou pelo menos para evitar a perda - comunicacional.

\footnotetext{
${ }^{1}$ Artigo derivado de monografia de graduação em Jornalismo, orientada pela professora Bárbara Assumpção e apresentada em julho de 2020.
} 
A relevância deste trabalho é, principalmente, que cada vez mais se faz necessário que os jornalistas tenham boas noções de comunicação visual, principalmente considerando a aproximação - ou acúmulo - de funções nas redações, cada vez menores; e também o surgimento de veículos independentes produzidos por jornalistas que se encontram fora do mercado de trabalho - ambas situações derivadas da crise que o jornalismo enfrenta na sua fase digital. Ainda, com novas possibilidades de expressão trazidas pela plataforma digital para o jornalismo (NUNES FREIRE, 2009), o potencial de ganho informacional que tem um jornalista que domina o campo da comunicação visual é muito maior do que daquele que o ignora.

Tomando um caminho um pouco mais filosófico e em busca de um resgate da dignidade do design jornalístico, este trabalho tem também o potencial de tornar mais explícita importância do design nos jornais. É graças à boa disposição de informação que a leitura e assimilação da mensagem é possibilitada, mas a trivialidade atribuída ao consumo dos jornais, bem como a desvalorização dos processos de produção jornalística, faz com que esse trabalho passe despercebido aos olhos da maioria. Vilém Flusser escreve

Se o design continuar se tornando cada vez mais o foco de interesse, e as questões referentes a ele passarem a ocupar o lugar das preocupações concernentes à ideia, certamente não mais pisaremos em chão firme. Eis aqui um exemplo disso: as canetas de plástico estão se tornando cada vez mais baratas e tendem a ser distribuídas de graça. O material de que são feitas praticamente não tem valor, e o trabalho, graças a uma tecnologia sagaz, é realizado por máquinas totalmente automatizadas. A única coisa que confere valor a essas canetas de plástico é o seu design, que é a razão de escreverem. Esse design não deixa de ser uma coincidência de grandes ideias que, provenientes da ciência, da arte e da economia, fecundaram-se e complementaram-se de maneira criativa. $E$, no entanto, tendemos a não prestar nenhuma atenção nesse design, razão pela qual as canetas tendem a ser distribuídas gratuitamente, como suportes publicitários, por exemplo. Essas grandes ideias por trás da caneta são tratadas com o mesmo desdém com que se trata seu material e o trabalho necessário para produzi-las (FLUSSER, 2018).

Cabe também atentar-se para o fato de que a evolução do design dos jornais sempre foi muito importante para manter o modelo impresso e seus desdobramentos na plataforma digital no páreo de outras plataformas jornalísticas, como a televisão, por exemplo. Até o século XX, a diagramação de um jornal não passava da condensação de palavras uma atrás da outra, quando muito, divididas em colunas. Era difícil fazer 
uma leitura dinâmica do conteúdo, pois quase não havia indicações de hierarquia da informação ou margens de respiro. Esse modelo não causava rejeição dos leitores à época porque era dominante, e não havia grande variação entre os jornais. Hoje a competição, tanto entre jornais quanto entre diferentes mídias, torna um design ruim insustentável em termos de mercado e audiência (HARROWER, 1997, p. 3). Portanto, é justo resgatar a importância desse campo do conhecimento dentro da comunicação jornalística.

\section{O papel do dispositivo na informação jornalística}

O tema do presente trabalho é o papel do dispositivo na informação jornalística através dele veiculada. Para começar, portanto, é necessário definir o que é dispositivo. Charaudeau (2006, p. 214) define que o dispositivo "é uma maneira de pensar a articulação entre vários elementos que formam um conjunto estruturado, pela solidariedade combinatória que os liga". Assim, o dispositivo dos veículos jornalísticos não é apenas seu suporte físico, que hoje se divide entre impresso e digital, mas o design dos jornais, e este atribui ao conteúdo jornalístico significado além da mensagem, pois

$$
\begin{aligned}
& \text { O dispositivo constitui o ambiente, o quadro, o suporte físico } \\
& \text { da mensagem, mas não se trata de um simples vetor } \\
& \text { indiferente ao que veicula, ou de um meio de transportar } \\
& \text { qualquer mensagem sem que esta se ressinta das } \\
& \text { características do suporte. Todo dispositivo formata a } \\
& \text { mensagem e, com isso, contribui para lhe conferir um } \\
& \text { sentido (CHARAUDEAU, 2006, p. 104). }
\end{aligned}
$$

Admite-se então que o jornal não é responsável apenas pela informação publicada, mas também pela forma como é publicada, uma vez que ela também constitui a informação, assim como a mensagem. Ainda segundo Charaudeau (2006), a apresentação formal das notícias é feita

através da paginação (primeira página, rubricas, fotos, desenhos, gráficos, tabelas, tipos de colunas, molduras, etc) e da titulagem (títulos, pré-títulos, subtítulos, leads). Tais elementos constituem formas textuais em si e têm uma tripla função: fática, de tomada de contato com o leitor, epifânica, de anúncio da notícia, e sinóptica, de orientação ao percurso visual do leitor no espaço informativo do jornal (CHARAUDEAU, 2006, p. 233).

Ao entrarmos na fase digital do jornalismo, com início nos anos 1990, as possibilidades expressivas proporcionadas pelo computador tornam o design um dos elementos mais importantes da enunciação jornalística, diminuindo inclusive a distância entre a produção e a formatação da notícia (NUNES FREIRE, 2009). Dessa 
forma, torna-se cada vez mais importante ao profissional de jornalismo o domínio teórico e prático das principais noções de comunicação visual.

\section{O Guia}

\section{A escolha pelo gênero textual instrucional}

O guia é a maneira mais direta de orientar alguém a respeito de como fazer. Como o objetivo deste trabalho é, além de explicitar a influência da forma na mensagem jornalística, servir como material de consulta para jornalistas eventualmente incumbidos de diagramar o conteúdo que produziram, o gênero instrucional parece ser o que mais cabe à situação.

O esqueleto do guia foi elaborado a partir, mas não exclusivamente, da definição de Charaudeau (2006) do que compõem o dispositivo de enunciação jornalística. Para o autor, esses elementos são primeira página, rubricas, fotos, desenhos, gráficos, tabelas, tipos de colunas, molduras, além de títulos, pré-títulos, subtítulos e leads. Além disso, serão abordados o uso de cores, o uso de espaços em branco e a identidade visual (marca) do jornal de maneira geral.

Antes de desmembrar os elementos da diagramação e trata-los particularmente, a introdução do Guia de Boas Práticas Visuais para Jornalistas vai resgatar a importância do design e reaproximar as funções de jornalista e designer, considerando sobretudo as transformações no mercado de trabalho na fase digital do jornalismo (NUNES FREIRE, 2009). Além disso, a seção "Do bom uso da regra. E do mau" trata da seguinte questão: existe uma evolução real entre jornais impressos ou digitais ou são apenas a reprodução de um mesmo modelo em plataformas diferentes? Depois, uma breve análise da versão online de um dos jornais mais acessados do Brasil, somando plataformas impressa e digital, a Folha de S. Paulo, vai servir para definir os elementos básicos de uma homepage jornalística (manchete, corpo, menu, seções da página, etc). Principalmente, essa análise visa ambientar o leitor e traçar o caminho para as próximas seções do guia, referentes às características dos elementos identificados.

\section{Bases teóricas utilizadas para a produção do guia}

Além dos supracitados, outros elementos abordados serão a identidade visual, tendo como referência análises de Dias Lessa (Dois Estudos de Comunicação Visual, 1995); 
o grid (colunas, módulos, molduras) a partir da análise de Kepes (Language of Vision, 1969) de subdivisão e padronização em uma configuração visual; as escolhas tipográficas (títulos, pré-títulos, subtítulos e leads, texto) a partir da obra do tipógrafo Bringhurst (Elements of Typographic Style, 2004); o emprego das cores com base na análise do uso de cor na informação por Guimarães (A cor como informação, 2003) e cor na composição visual por Arnheim (Arte e Percepção Visual, 2004); a interação entre elementos, produção de hierarquia e equilíbrio a partir de Kepes (Language of Vision, 1995) e Arnheim (Arte e Percepção Visual, 2004); o uso do espaço em branco com base em Collaro (Projeto Gráfico: Teoria e Prática da Diagramação, 1987), Kepes (Language of Vision, 1995) e Arnheim (Arte e Percepção Visual, 2004); e o uso de mídias (fotos, vídeos, desenhos, áudios, link), estudado a partir de uma observação empírica nos cinco jornais brasileiros mais acessados, somando plataformas impressa e digital.

O conjunto dessas diretrizes vai formar uma base de conhecimento suficientemente técnica para começar a trabalhar com a disposição gráfica das notícias e desenvolver esse domínio também a partir da prática, uma vez que a produção do Guia de Boas Práticas Visuais para Jornalistas não implica que exista uma única forma correta de se trabalhar, visando apenas a estabelecer conceitos essenciais.

Em termos de organização formal do guia, a principal referência para este trabalho é o "Guia NFL ESPN". Trata-se de uma página do canal esportivo ESPN que disponibiliza "O guia definitivo para você saber tudo de futebol americano". Possui um menu no topo, com as seções da página, e essas são acessadas através da rolagem ou pelo clique, através de pontos âncora posicionados ao longo da página. É um guia com muitas imagens e textos diretos e curtos, garantindo a atenção do leitor.

Quanto à linguagem utilizada, serão priorizados os textos curtos e diretos; o uso de imagens para complementar a informação verbal; a não utilização de termos técnicos, a menos que sejam indispensáveis para a compreensão; e a estruturação do texto em tópicos separados para cada elemento abordado no guia, como recomendam as publicações "Creating a Guide" e "Creating a 'How to Guide'", elaboradas pela Bath University, na Inglaterra. 


\section{Principais referências visuais para a produção do guia}

Em termos mais visuais do que de navegação, busquei referências em "handbooks". São manuais, normalmente organizados institucionalmente para funcionários de uma marca. O do Facebook foi a principal referência para o guia desenvolvido nesse trabalho. Trata-se de um livro pequeno, com textos curtos e páginas coloridas, que mais uma vez garantem ao produto uma noção de dinamismo.

Outra importante referência visual é o manual da marca $^{2}$ do centro de arte londrino Barbican. Também se trata de um material informativo, que possui as mesmas características principais do handbook do Facebook: textos curtos, variação de cores de acordo com a seção do texto, dinamismo visual. Aproveitando-se da plataforma digital, esse manual não possui páginas, mas sim seções acessadas através da rolagem vertical. A página utiliza uma única fonte (a mesma que é característica da marca Barbican, a Futura) e poucas cores - além de preto e branco, há uso de laranja, roxo e verde vibrantes. Algumas imagens do guia são animadas. Deve ser levado em conta, no entanto, que o manual da marca do Barbican já é bastante conciso quanto ao seu conteúdo, o que aumenta a ideia de dinamismo do site e não vai acontecer necessariamente em páginas com as mesmas características se essas possuírem muito conteúdo escrito.

Por sua vez, o guia produzido por este trabalho não responde a uma marca ou identidade previamente construída. Portanto, não precisa remeter a um conjunto de características (cor, tipografia) específico e aproveito-me disso para torná-lo o menos visualmente repetitivo possível. O objetivo dessa abordagem é evitar cair na monotonia visual. Em Arte e Percepção Visual (2004), Arnheim escreve que

O gradiente hierárquico aproxima-se de zero quando um padrão se compõe de muitas unidades de igual peso. Os padrões repetitivos de papel de parede ou das janelas de altos edifícios conseguem equilíbrio por homogeneidade. [Obras com gradiente hierárquico baixo] apresentam um mundo no qual se sente no mesmo lugar onde quer que se vá. (ARNHEIM, 2004, p. 21)

Por outro lado, deve-se manter em mente que se trata de um material do gênero textual instrucional e, portanto, seu principal objetivo é passar conhecimento ao leitor. Retomando Arnheim, pode-se inferir que a simplicidade é uma característica

\footnotetext{
${ }^{2}$ Brand / Barbican Guidelines. Disponível em: https://guidelines.barbican.org.uk/brand/. Acessado em 16 de maio de 2020.
} 
que contribui para a assimilação da informação, uma vez que para o autor a simplicidade é

a experiência subjetiva e julgamento de um observador que não sente nenhuma dificuldade em entender o que se the apresenta. Pode-se aplicar à simplicidade o que Spinoza disse sobre a ordem. Segundo uma passagem de Ética, acreditamos firmemente que existe ordem nas próprias coisas mesmo que não saibamos nada a respeito delas ou de sua natureza. "Pois quando as coisas se dispõem de tal modo que ao nos serem apresentadas pelos sentidos podemos facilmente imaginá-las e, em consequência, com facilidade recordá-las, as chamamos de bem ordenadas e, no caso oposto, de mal ordenadas ou confusas. (ARNHEIM, 2004, p. 47)

Sendo assim, limita-se o número de cores - excluindo preto e branco - no guia a quatro matizes: amarelo, azul, rosa e vinho, com variações de brilho; e o uso dos tipos fica limitado a duas famílias tipográficas: uma com serifa, Georgia, e uma sem serifa, Helvetica, sendo feito também uso de suas variações de tamanho e peso.

Um fator decisivo na escolha das fontes foi a sua presença nos computadores. Dependendo do navegador e do dispositivo utilizado pelo leitor, apenas tipos instalados no dispositivo em uso são exibidos corretamente. Por isso, para páginas da web, o ideal é utilizar fontes que costumam vir instaladas nos computadores junto com o sistema operacional. O Instituto de Tecnologia de Massachusetts (MIT) hospeda em seu site uma lista de famílias tipográficas ${ }^{3}$ mais "seguras" para uso na web, de acordo com a quantidade de sistemas operacionais em que estão presentes. Georgia e Helvetica são famílias que constam nessa lista como fontes seguras.

\section{Por que um guia digital?}

O guia elaborado leva em conta as transformações e possibilidades acarretadas pela ascensão do consumo digital de notícias. Diante disso, o formato escolhido para sua apresentação foi um site. Primeiro, foi considerada a opção de criar um site para hospedar um documento em pdf, que seria o guia. Porém, o documento pdf é o padrão de formato utilizado para impressões, ou reproduções de impressões, como em eBooks. As análises levantadas na confecção do presente trabalho criticam o uso das plataformas digitais por jornais, entre outros motivos, por priorizarem uma reprodução do material impresso ao invés de elaborar um conteúdo específico que

\footnotetext{
${ }^{3}$ Safe Web Fonts. Disponível em: https://web.mit.edu/jmorzins/www/fonts.html. Acessado em 2 de maio de 2020.
} 
aproveite possibilidades do formato digital das quais o veículo impresso carece. Assim, seria incoerente a escolha do pdf como formato.

Além disso, o site é mais dinâmico que o documento pdf e a opção por âncoras nas páginas - marcação de um ponto específico na rolagem - torna a navegação pelo conteúdo do guia mais simples e dinâmica. Todo o conteúdo está apresentado em uma mesma página, do sumário às conclusões, e botões no topo da página ajudam o leitor que quer encontrar uma seção específica. Da mesma forma, se deseja navegar por todo o conteúdo, pode usar a rolagem da página normalmente.

\section{Pesquisa empírica por guias e manuais na internet: "Como fazer um guia digital - Pesquisa Google"}

Mais por curiosidade do que esperando encontrar algo de útil para este trabalho, pesquisei no Google: "Como fazer um guia de digital". Apesar da ferramenta ter me apresentado "aproximadamente 143.000 .000 resultados $(0,41$ segundos)", os principais são plataformas como Flipsnack, Yumpu, Paper Turn ou FlipBook Creator. O serviço oferecido por essas plataformas é o de simular uma virada de página de papel na tela do computador.

Nada nessa linha de raciocínio valoriza o potencial da plataforma digital em comparação com a plataforma impressa. Na verdade, pelo contrário, insinua que o digital tem uma falta imperdoável - a virada de página. O Flipsnack escreve "Use o editor online da Flipsnack para enviar o seu guia em pdf e fazer seu guia parecer tão profissional quanto a versão impressa".

\section{O desafio de conciliar experimentação e informação}

Também encontrei em minha pesquisa um ótimo exemplo de exploração do potencial da plataforma digital na criação de um guia: o Livro da Marca Globo ${ }^{4}$. Enquanto é um ótimo exemplo de exploração de recursos digitais, talvez seja um exemplo ruim de manual. A página inicial tem um único elemento em destaque: uma animação interativa - que se mexe e muda de cor quando você passa o mouse - que tem a forma circular e que lembra a logo da Globo, mas não é clicável e nem possui nenhuma função informativa.

\footnotetext{
${ }^{4}$ Globo - Livro da Marca. Disponível em: https://www.livrodamarcaglobo.com/\#/. Acessado em 17 de maio de 2020.
} 
Quanto à navegação, existem duas opções, rolagem vertical para baixo, que passa pelos títulos das seções: A marca, O sistema de identidade, O volume da marca, etc. Para acessar o conteúdo das seções é preciso "abri-las" clicando em um símbolo posicionado próximo ao título. O conteúdo de cada seção é bastante breve. Dentro de algumas seções maiores há rolagem horizontal. No fundo de cada título de seção há uma animação. Outra opção de navegação é um menu ao lado da barra de rolagem, vertical. Ele só aparece quando passamos o mouse por cima e é composto por símbolos e não títulos textuais.

Estamos analisando uma página que é diferente da maioria dos sites, que são muito influenciados pelo design gráfico impresso, como expõe Rafael Cardoso em seu livro Design para um Mundo Complexo:

Muitas páginas no ambiente virtual obedecem a uma configuração muito próxima à de uma primeira página de jornal: cabeçalho ao topo; organização da informação em colunas e blocos; emprego de títulos acima dos textos e legenda abaixo das imagens; presença de índice, sumário ou outro sistema de remissão à parte "interna" (CARDOSO, 2013, p. 209).

A navegação não é a usual (paginação ou rolagem vertical). O cabeçalho não fica no topo, mas do lado direito da página, acompanhando a rolagem. Toda seção tem pelo menos uma animação. É um bom exemplo de inovação e uso consciente dos potenciais da plataforma digital. Nenhuma parte desse manual da marca Globo faria sentido se fosse impresso.

Minha ressalva enquanto produtora de um guia próprio é que o excesso de elementos inovadores pode confundir o usuário, e embora toda experimentação seja válida como experiência digital, e mais do que válida, necessária, dado que o potencial da plataforma é muito subutilizado, como demonstrou o item anterior, talvez o lugar de tanta experimentação de uma só vez não seja em um material instrucional. Afinal, quem acessa o manual da marca está buscando informações sobre o seu uso correto, e o excesso de elementos a serem desvendados pode ser prejudicial à transmissão dessa informação. 


\section{O Guia Publicado}

O Guia de Boas Práticas Visuais Para Jornalistas está hospedado no domínio "designparajornalistas.com". Foi dividido em treze seções além da capa: Introdução; Do Bom Uso da Regra. E do mau; Principais elementos do jornal digital; Identidade Visual do jornal; Grid; Cores; Tipografia; Interação e equilíbrio; Hierarquia; Espaços em branco; Mídia; UX; e Bibliografia. Mais da metade das seções conta com elementos interativos ou sensíveis ao mouse.

\section{GUIA DE BOAS} PRÁTICAS VISUAIS PARA JORNALISTAS

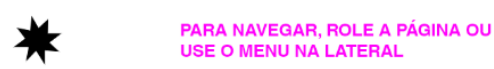

USE O MENU NA LATERAL

Imagem 1: Guia de Boas Práticas Visuais Para Jornalistas: Capa

Imagem 2: Guia de Boas Práticas Visuais Para Jornalistas: Introdução 
computadores, podem não ser exibidas corretamente em qualquer dispositivo.

Fontes com serifa ajudam o olho a seguir a linha que está sendo lida, mas para textos curtos, fontes sem serifa funcionam melhor em dispositivos móveis. Fontes que imitam caligrafia ou com muitos detalhes devem ser evitadas, com exceção talvez de algum título especial; mesmo assim, é melhor escolher fontes estilizadas, com personalidade, mas visualmente simples.

QUE FONTEÉ ESSA?

\title{
Usando uma fonte com serifa?
}

Combinar com uma sem serifa normalmente dá certo.

\section{QUE FONTE É ESSA?}

\section{Usando uma fonte sem serifa?}

O contrário também funciona.

Imagem 3: Exemplo de interação: Guia de Boas Práticas Visuais Para Jornalistas: Tipografia (Recorte) 1

\begin{abstract}
computadores, podem não ser exibidas corretamente em qualquer dispositivo.

Fontes com serifa ajudam o olho a seguir a linha que está sendo lida, mas para textos curtos, fontes sem serifa funcionam melhor em dispositivos móveis. Fontes que imitam caligrafia ou com muitos detalhes devem ser evitadas, com exceção talvez de algum título especial; mesmo assim, é melhor escolher fontes estilizadas, com personalidade, mas visualmente simples.
\end{abstract}

\section{Baskerville Old Face}

+ Gotham Light

\section{uma fonte}

com serifa?

Combinar com uma sem serifa

normalmente dá certo.

QUE FONTE É ESSA?

\section{Usando uma fonte sem serifa?}

O contrário também funciona.

Imagem 4: Exemplo de interação: Guia de Boas Práticas Visuais Para Jornalistas: Tipografia

(Recorte) 2 


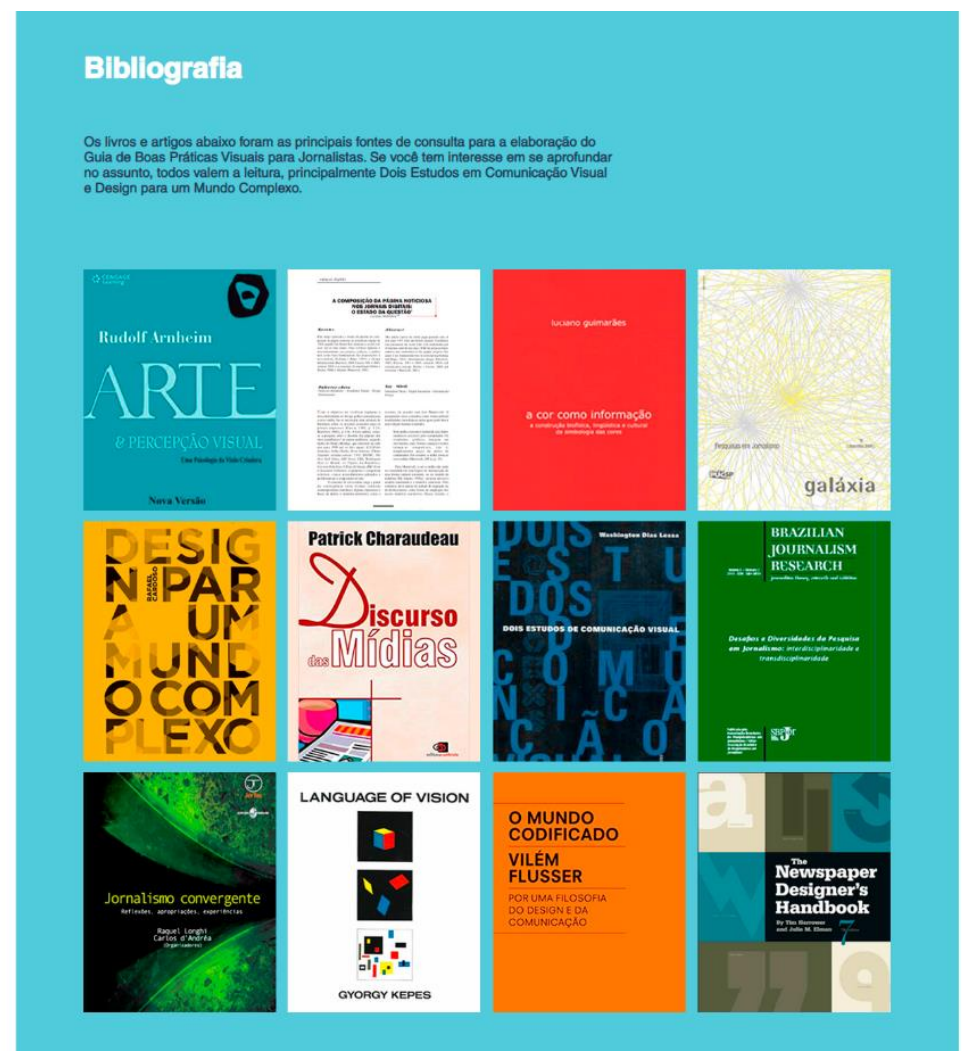

Imagem 5: Guia de Boas Práticas Visuais Para Jornalistas: Bibliografia

\section{Adaptação para dispositivos móveis}

Na versão para celular, algumas ferramentas interativas tiveram que ser desativadas porque não funcionavam bem, mas o texto do guia foi mantido integralmente. No cabeçalho da página mobile há um aviso: "Este Guia é melhor visualizado em sua versão para computador. Ao acessar pelo celular ou outro dispositivo móvel, você perde boa parte do conteúdo interativo.". Também foi adicionado um botão de ações rápidas, com a opção de voltar ao topo da página e de compartilhar o link do guia via WhatsApp, que pode ser usado para salvar e ler depois. 


\section{GUIA DE BOAS \\ PRÁTICAS \\ VISUAIS PARA}

Envie o link para ler depois

ఐ

Voltar ao topo

$\uparrow$

Imagem 6: Botões de ação rápida.

๑ designparajornalistas.com

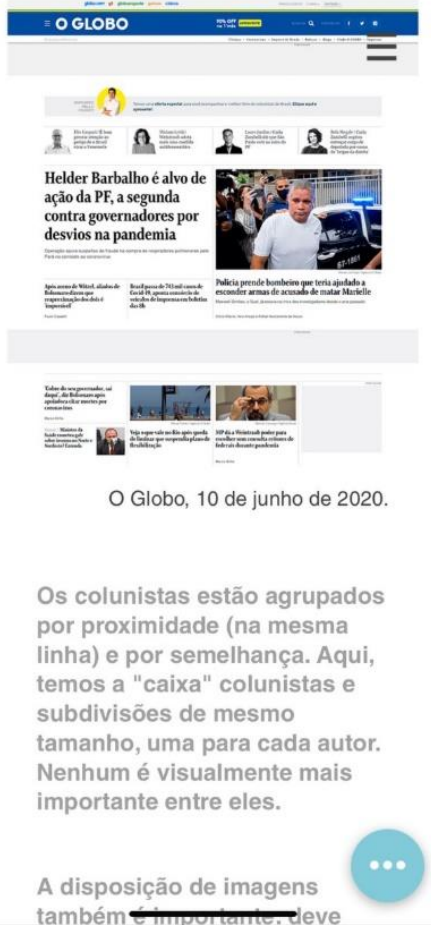

Imagem 7: Interação desativada, sem perda de sentido. 


\section{Considerações finais}

A elaboração do Guia de Boas Práticas Visuais para jornalistas exigiu algumas etapas. Primeiro, buscar no desenvolvimento histórico do processo de confecção dos jornais porque o conteúdo e aparência das publicações eram tão distantes e em que circunstâncias têm se aproximado. Não se aproximam necessariamente numa busca por melhorar a qualidade da informação, mas sim por questões de mercado, entre elas a diminuição das redações e a proliferação de veículos independentes, e identificada essa questão, a proposta do guia é fornecer conteúdo que possa qualificar esse processo.

Depois, identificar que configurações visuais estão consolidadas e por quê. Arnheim (2004) escreveu que "se um aparelho de televisão e uma máquina de escrever parecessem exatamente iguais, seríamos privados de uma correspondência simples e desejável entre forma e função". Os jornais digitais, hoje, mesmo após inúmeras transformações e adaptações tecnológicas, se parecem com jornais de papel. Isso por si só não é ruim ou indesejável, mesmo porque a instituição "jornal" passa confiança ao leitor. Mas repetir exaustivamente as mesmas características visuais inibe ou pelo menos desacelera a evolução desses projetos gráficos e, consequentemente, a expressão visual dos jornais não acompanha ou se beneficia tanto quanto poderia das novas possibilidades que a plataforma digital oferece. A observação empírica e as leituras a respeito da composição de páginas noticiosas digitais mostraram que em sua maioria os jornais digitais se limitam a reproduzir a estrutura e aparência dos veículos impressos. E se os profissionais do jornalismo se ocupam de informação, não faz sentido querer aproveitar mais recursos disponíveis para entregá-la de forma cada vez melhor ao consumidor?

A partir desse cenário de estagnação criativa, as recomendações que compõem o guia aqui produzido incentivam a atenção a princípios fundamentais da informação, como legibilidade, clareza e organização; mas também, sem deixá-los de lado, tenta demonstrar que a plataforma digital permite mais experimentação, originalidade e interatividade do que é observado hoje.

Por sua vez, o processo de criação do Guia em formato de site evidenciou algumas dificuldades dessa área. Embora eu tenha me sentido muito livre para experimentar com cores diferentes, demorou algum tempo até encontrar o equilíbrio entre aproveitar bem o espaço infinito do suporte digital, valorizando o seu conteúdo, e a 
criação acidental de alguns "vazios" no layout. Além disso, buscando uma navegação simples e dinâmica, optei por uma página única com seções identificadas a partir de pontos âncora. Conforme fui preenchendo a página com o conteúdo, seu carregamento foi ficando mais lento. Então, me lembrei que a internet no Brasil é bem mais lenta do que em outros lugares do mundo, e imagino que esse seja um receio por parte de alguns veículos jornalísticos.

Também durante a criação do site tive alguns imprevistos: minhas primeiras opções de cores e fontes não ficaram tão boas, e tive que flexibilizar o projeto inicial. Percebi que o que funcionava nas minhas referências visuais não necessariamente funcionaria no meu projeto - o que me lembra que o design não é um conjunto de regras, mas um campo em constante evolução, e que sua prática consiste em combinar e recombinar elementos visuais infinitos, em possibilidades infinitas - e algumas funcionam melhor do que outras em determinados contextos, mas elas nunca serão esgotadas.

Uma das questões que este trabalho não deu conta de responder foi a seguinte: o quanto é experimentação suficiente e o quanto é experimentação demais? Não se pode quebrar de uma vez o contrato estabelecido com o leitor de que um jornal se parece com um jornal, e essa identificação é fundamental semanticamente para o gênero informativo, porque estabelece familiaridade e confiança. Mas, ao mesmo tempo que caminhamos lentamente incorporando novos recursos já consolidados na plataforma digital fora dos jornais (vídeos e áudios, por exemplo, estão por todas as redes sociais), outros vão surgindo e a linha de chegada se distancia conforme corremos.

Outra questão que me ocorreu ao longo da realização do guia, mas que também não foi explorada, foi: o quanto a dificuldade de acesso à internet por parte da população brasileira influencia na evolução das páginas noticiosas digitais? Como conciliar sinal de internet ruim e acesso exclusivamente pelo celular - condições muito comuns para boa parte da população brasileira - e incorporação e aproveitamento das novas tecnologias para informar o máximo de pessoas possível?

\section{Referências Bibliográficas}

ARNHEIM, Rudolf. Arte e percepção visual: uma psicologia da visão criadora. São Paulo: Pioneira Editora, 2004. 
CARDOSO, Rafael. Design para um Mundo Complexo. São Paulo: Cosac Naify, 2013. CHARAUDEAU, Patrick. Discurso das mídias. São Paulo: Contexto, 2006.

DIAS LESSA, Washington. Dois Estudos de Comunicação Visual. Rio de Janeiro: Editor UFRJ, 1995.

FLUSSER, Vilém. O Mundo Codificado - por uma filosofia do design e da comunicação. Ubu Editora, 2018.

GÁSCON, J. F. F. Impacto Visual na Imprensa Digital. Uma pesquisa espanhola empírica. Brazilian Journalism Research, vol. 6, núm. 2, pp. 120-137, 2010. SBPJor. Brasília, Brasil.

GUIMARÃES, Luciano. A cor como informação: a construção biofísica, lingüística e cultural da simbologia das cores. São Paulo: Editora Annablume, 2000.

HARROWER, Tim.The Newspaper Designer's Hadbook. 4. ed. McGraw-Hill Education, 1997.

KEPES, Gyorgy. Language of Vision. Londres: Dover Publications, 1995.

MOHERDAIU, Luciana. A composição da página noticiosa nos jornais digitais: 0 estado da questão. Sessões do Imaginário, núm. 21, pp. 63-72, agosto, 2009. Pontifícia Universidade Católica do Rio Grande do Sul. Porto Alegre, Brasil.

NUNES FREIRE, Eduardo. O design no jornal impresso diário. Do tipográfico ao digital. Galáxia, núm. 18, pp. 291-310, dezembro, 2009. Pontifícia Universidade Católica de São Paulo. São Paulo, Brasil. 